\title{
MÉTODOS DE INVESTIGACIÓN FINANCIERA PARA DETECTAR Y PROBAR EL DELITO DE LAVADO DE DINERO
}

\author{
JENNIFER ISABEL ARROYO CHACÓN \\ Contraloría General de la República \\ prof.jenniferarroyo@yahoo.com
}

\section{RESUMEN}

Las ganancias generadas por la comisión de actos delictivos tales como: narcotráfico, tráfico ilegal de personas, armas, animales y demás genera utilidades que son ingresadas al ciclo normal de la economía como si provinieran de fuentes legales, lo cual se conoce como el delito de lavado de dinero o blanqueamiento de capitales. Los métodos de investigación financiera permiten obtener prueba indiciaria de la comisión de estas faltas, al determinar que los gastos y el nivel de vida del investigado es superior al que le permiten sus ingresos legalmente declarados, y que por lo tanto, se puede presumir que provienen de un delito, lo cual unido a otras pruebas demuestran la comisión del delito de lavado de dinero. Estos métodos están: método del efectivo, método de rastreo de un depósito específico, método de Depósito bancario, método del Ingreso-Gasto, método del Valor Neto. Estos métodos se enfocan en distintas áreas de investigación pero todos permiten demostrar que el investigado posee fuentes de ingresos de origen ilicito.

PALABRAS CLAVES: MÉTODOS DE INVESTIGACIÓN FINANCIERA, LAVADO DE DINEROY PRUEBA INDICIARIA.

\section{ABSTRACT}

Profit from criminal acts such as drug, human, weapon and animal trafficking, and other benefits illegally generated enter the normal economic cycle as if they came from legal sources, a process known as money laundering or money washing. Financial research methods allow access to circumstantial evidence of the commission of these offenses by determining whether a person's expenses and living standards are higher than his/ her legally declared income, and, therefore, it can be assumed that such income comes from criminal activities and from money that has been washed. Such methods include the Cash Method, the specific deposit tracking method, the Bank Deposit Method, the Income vs. Expenditure Method, the Net Worth Method among others. These methods focus on different areas of research, but all of them can show if someone under investigation has illegal income sources.

KEYWORDS: METHODS OF FINANCIAL INVESTIGATION, MONEY LAUNDERING AND CIRCUMSTANTIAL EVIDENCE.

\section{INTRODUCCIÓN}

La comisión de delitos tales como el narcotráfico, trata de personas, tráfico de órganos, de animales, y demás vinculados generan ganancias que lógicamente son el atractivo para su comisión; no obstante, estos recursos son útiles sólo si logran ingresarse al ciclo de la economía formal como provenientes de fuentes lícitas para ser utilizados libremente, con lo cual se configura el delito de lavado de dinero o blanqueamiento de activos.

Ahora bien, muchas veces probar la comisión del delito de lavado de dinero resulta difícil toda vez que sus ejecutores buscan maneras para no dejar rastro de ello, de tal manera que se debe recurrir a la prueba indiciaria la cual junto con otras pruebas directas permitan demostrar que se ha cometido dicho delito. 
De tal manera, que los métodos de investigación financiera, que se basan en analizar el efectivo, los depósitos bancarios, los ingresos y gastos, y un análisis comparativo entre las condiciones de vida del investigado antes de la actividad lucrativa y después de que se presume se ha cometido el delito de lavado de dinero, permiten generar prueba indiciaria en su contra.

Los métodos de investigación financiera pretenden demostrar que los gastos y nivel de vida del investigado no resultan acordes con sus ingresos legalmente declarados y que por lo tanto queda un saldo al descubierto que presumiblemente proviene del delito de lavado de dinero.

De tal manera que los resultados de este tipo de investigación generan prueba indiciaria, la cual unida a otras fuentes de prueba, pueden demostrar la comisión de este delito y obtener una condenatoria en firme.

Este tema resulta de gran relevancia en Costa Rica que cada vez está siendo más afectado para este tipo de delitos, razón por la cual el presente artículo pretende explicar estos métodos, con el fin de que el lector puede emplearlos en sus investigaciones, con el fin de detectar y probar este tipo de delitos.

De tal manera que a continuación se explica brevemente como se aplican estos métodos, unos más sencillos y otros más completos según el grado de profundidad con el que se quiera y pueda realizar la investigación.

\section{Lavado de dinero}

\section{¿Qué se entiende por lavado de dinero?}

El lavado de dinero es un delito penal que ha ido en incremento en los últimos años, y que cada vez adquiere distintas formas, pues quienes lo realizan buscan nuevas maneras de llevarlo a cabo sin ser detectados, vulnerando los mecanismos de control establecidos y obligando a las autoridades a ser más ingeniosos para detectarlos y sancionarlos.

La doctrina ha definido esta figura de la siguiente manera:

El Lavado de Dinero es el proceso de tomar dinero en forma ilegal, derivado de actividades ilícitas y darle al mismo la apariencia de haber provenido de fuentes legítimas. El objetivo de cualquier esquema de lavado de dinero es el de utilizar capital proveniente de actividades ilícitas y darle la apariencia de que proviene de actividades legítimas (Centro de Investigación Jurídica, 1998, p.3).

10) El blanqueo de dinero y los diferentes tráficos ilegales que pueden constatarse en la realidad internacional (tráfico de drogas, tráfico de armas, tráfico de sustancias químicas o radioactivas, tráfico de seres humanos) son en realidad las dos caras de una misma moneda. Son dos actividades delictivas indisolublemente ligadas.

La venta y distribución de los objetos a los que se ha hecho referencia genera fabulosos beneficios económicos que necesitan ser reciclados e introducidos en los circuitos comerciales y financieros y que, a su vez, sirven de fuente de financiación, son el soporte vital de las organizaciones que se dedican a esa actividad, permitiendo su consolidación como tales grupos organizados y la ampliación de sus actividades ilícitas. Parece evidente, por tanto, que nos encontramos ante un círculo vicioso en el que todos los aspectos están estrechamente interrelacionados (Alonso, 2011, p. 4).

En síntesis, podemos definir lavado de dinero como la actividad que busca convertir el dinero obtenido a través de un acto ilícito en bienes y servicios lícitos que no puedan ser rastreados a través del delito subyacente. 
El lavado de dinero se puede aplicar en todo tipo de activos, no obstante, el efectivo es el bien que más es objeto de este tipo de delito toda vez que debe introducirse a la economía como limpio.

Si bien comúnmente el lavado de dinero se asocia a delitos de narcotráfico, ésta no es la única actividad criminal que da pie a un lavado de dinero, otros delitos tales como la corrupción en la función pública pueden originar un lavado, toda vez que el funcionario público que ha recibido dadivas necesita buscar mecanismos para desviar ocultar ese dinero obtenido por un delito y transformarlo en bienes y servicios lícito que pueda utilizar.

De lo contrario, incurre en un enorme riesgo de ser detectado, pues quedaría evidencia fácilmente localizable de haber recibido un pago improcedente, de algún proveedor, por ejemplo, lo cual afectaría no sólo al funcionario público corrupto, sino al privado corruptor, por lo cual se buscan este tipo de estrategias para hacer perder la pista del delito y poder disfrutar las bienes obtenidos de forma ilícita.

Dentro de los objetivos que se buscan con el lavado de dinero se encuentran los siguientes:

- Hacer que la ganancia obtenido de manera ilegal aparente ser la utilidad de una actividad lícita.

- Eludir la sanción penal de quien cometió el delito, y proteger la ganancia obtenida del embargo y confiscación por las autoridades que persiguen y sancionan la actividad ilícita que le da origen a dichos réditos.

- Hacer posible la transferencia de fondos alrededor del mundo para gozar y financiar actividades criminales adicionales.

\section{Normativa en contra del lavado de dinero}

El delito de lavado de dinero afecta a todos los países, por lo tanto, se ha aprobado tanto normativa nacional como internacional sobre el tema, entre los más destacados están:

- Convención de las Naciones Unidas contra el tráfico ilícito de estupefacientes y sustancias sicotrópicas. Convención de Viena del 19 de diciembre de 1988.

- Convenio Europeo sobre Lavado de Dinero, Detección, Embargo y Confiscación de los productos de un delito. Convenio de Estrasburgo. Del 8 de noviembre de 1990.

- Tratado de la Unión Europea relativa al lavado de Capitales, Identificación, Seguimiento, Embargo, Incautación y Decomiso de los instrumentos y productos del delito. 2005.

- Convención de las Naciones Unidas contra la Delincuencia Organizada-Transnacional. Convención de Palermo del 12 de diciembre del 2000.

- Convención de las Naciones Unidas contra la Corrupción. Convención de Merida. Del 8 de diciembre del 2003.

- Comité de Supervisión Bancaria de Basilea. Principios Básicos para una Supervisión Bancaria Efectiva. 1997.

- Comité de Supervisión Bancaria de Basilea. Metodología de los Principios Básicos. 1999.

- Modelo de las Naciones Unidas para la Legislación en el Lavado de Dinero, Confiscación y cooperación internacional con relación al producto del crimen. 2005.

- $\quad$ Principios del Grupo Wolfsburg. 2002.

Para el caso de Costa Rica se aplica la Ley Nº 8204 denominada Reforma integral Ley sobre estupefacientes, sustancias psicotrópicas, drogas de 
uso no autorizado, actividades conexas, legitimación de capitales y financiamiento al terrorismo, la cual tipifica el delito de lavado de dinero de la siguiente manera:

\section{Artículo 69.}

Será sancionado con pena de prisión de ocho (8) a veinte (20) años:

a) Quien adquiera, convierta o transmita bienes de interés económico, sabiendo que estos se originan en un delito que, dentro de su rango de penas, puede ser sancionado con pena de prisión de cuatro (4) años o más, o realice cualquier otro acto para ocultar o encubrir el origen ilícito, o para ayudarle a la persona que haya participado en las infracciones, a eludir las consecuencias legales de sus actos.

b) Quien oculte o encubra la verdadera naturaleza, el origen, la ubicación, el destino, el movimiento o los derechos sobre los bienes o la propiedad de estos, a sabiendas de que proceden, directa o indirectamente, de un delito que dentro su rango de penas puede ser sancionado con pena de prisión de cuatro (4) años o más.

La pena será de diez (10) a veinte (20) años de prisión, cuando los bienes de interés económico se originen en alguno de los delitos relacionados con el tráfico ilícito de estupefacientes, sustancias psicotrópicas, legitimación de capitales, desvío de precursores, sustancias químicas esenciales y delitos conexos, conductas tipificadas como terroristas, de acuerdo con la legislación vigente o cuando se tenga como finalidad el financiamiento de actos de terrorismo y de organizaciones terroristas.

(Así reformado por el artículo $2^{\circ}$, punto $1 .$, aparte b) de la Ley de Fortalecimiento de la
Legislación contra el Terrorismo, № 8719 de 4 de marzo de 2009).

\section{Artículo 69 bis.}

Será reprimido con prisión de cinco (5) a quince (15) años quien, por cualquier medio y de manera directa o indirecta, recolecte, oculte, provea, promueva, facilite o de cualquiera otra forma coopere con la recolección o la entrega de los fondos, productos financieros, recursos o instrumentos, en el país o en el extranjero, con la intención o el conocimiento de que estos se utilicen o destinen al financiamiento de actos terroristas, aunque estos no lleguen a ejecutarse, o a organizaciones declaradas como terroristas, de acuerdo con el Derecho internacional, o que tengan fines terroristas.

El hecho podrá ser juzgado en Costa Rica, sin importar el lugar donde haya sido cometido.

(Así adicionado por el artículo $2^{\circ}$, punto 2., aparte c) de la Ley de Fortalecimiento de la Legislación contra el Terrorismo, N 8719 de 4 de marzo de 2009). (Asamblea Legislativa, 2009)

Aun cuando el lavado de dinero está reconocido nacional e internacionalmente como un delito fuertemente sancionado, y para su persecución los países destinan gran cantidad de recursos, el principal problema para perseguirlo está precisamente en encontrar el rastro de ese dinero ilícito que se ha tratado de desvirtuar a través del lavado, y lograr encontraran prueba suficiente que permita sancionar este tipo de delitos, labor difícil en este tipo de actos, que precisamente buscan ocultar el origen de los dineros ilícitos, y eliminar todo tipo de prueba de dicha actividad.

En consecuencia, resulta necesario recurrir a los métodos de investigación financiera, que se expondrán en el siguiente apartado del presente documento. 


\section{MÉTODOS DE INVESTIGACIÓN FINANCIERA}

\section{¿Qué son los métodos de investigación financiera?}

Los métodos de investigación financiera son aquellos instrumentos que permiten utilizar la información financiera para identificar y corroborar la actividad delictiva donde el sujeto ha generado dinero para financiar y extender, actividades ilegales y gozar de un estilo de vida derrochador y acumular riqueza.

A su vez, permite identificar los bienes obtenidos con dinero provenientes de la actividad ilícita para ser decomisados y confiscados a favor del Estado.

Utilizando los métodos de información financiera se puede determinar si el estilo de vida del investigado sobrepasa las capacidades que posee con sus ingresos ordinarios, es decir, que si con su salario como funcionario público podría cubrir los costos y gastos en los que incurre ordinariamente por el estilo de vida que lleva él y su familia.
Estos métodos permiten crear información indiciaria o indirecta, pues no permiten demostrar explícitamente la comisión de un delito pero si son hechos que demuestran que probablemente la obtención de bienes más allá de sus ingresos ordinarios se origine en un delito, entre ellos el lavado de dinero.

De tal manera, que estos métodos de investigación financiera se utilizan como complemento de otras pruebas que hagan lógicamente suponer que el investigado se encuentra involucrado con el lavado de dinero pero que constituyen una prueba muy importante y convincente para probar este tipo de delitos.

\section{Descripción de la metodología del análisis financiero}

La metodología del análisis financiero busca crear un "perfil" de la gestión financiera del investigado, en el cual se determina sus ingresos, sus gastos y sus deudas, en un momento dado o durante un periodo de tiempo determinado. Tal y como se muestra en la figura 1.

Figura 1

\section{PERFIL DE LA GESTIÓN FINANCIERA DEL INVESTIGADO}

\section{Ingresos lícitos}

- Salarios

- Honorarios reportados a Tributación.

- Otros ingresos legalmente conocidos

\section{Activos \\ - Propiedades a su nombre \\ - Condiciones del inmueble en el que habita y gastos incurridos en su mantenimiento. \\ - Cantidad y tipo de vehículos que posee.}

Fuente: Elaboración propia.

\section{Gastos ordinarios}

- Pago de colegiaturas

- Pago de estudios de sus hijos

- Pago de servicios conocidos como de "lujo"

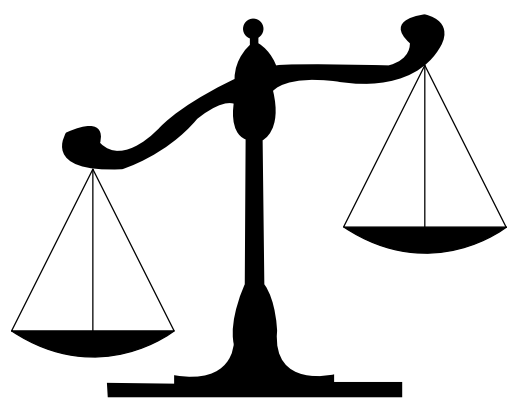

Estilo de vida

- Clubes a los que pertenece.

- Lugares a los que viaja y frecuencia.

- Sitios para vacacionar

- Restaurantes que visita

\section{Deudas}

- Nivel de endeudamiento

- Uso de tarjetas de crédito

- Préstamos con entidades de crédito no financieras

- Préstamos con organizaciones laborales. 
Para realizar dicho perfil se recurre a pruebas directas de ingresos legales o bienes ocultos, y pruebas indirectas de la actividad ilegal mostrando que los gastos del sujeto exceden las fuentes conocidas de fondos lícitos.

Una vez que se ha elaborado un perfil del sujeto conviene realizarse las siguientes preguntas:

1. ¿Los ingresos conocidos y legalmente reportados son suficientes para cubrir el nivel de gastos y estilo de vida del investigado?

2. ¿Ha existido alguna mejoría significativa de la calidad de vida del encausado en los últimos años, sin que haya acontecido un cambio en el nivel de ingresos del encausado que lo justifique?

3. ¿Tuvo el encausado un nivel de deuda alto en los últimos años, el cual ha logrado disminuir significativamente sin que exista una razón que justifique dicha mejoría?

4. En caso de que no existan razones que justifiquen dicha mejora en los ingresos del investigado. ¿Cuál es la fuente probable que origina dichos fondos?

5. ¿Cómo el sujeto dispuso de fondos o bienes conocidos para haber estado en posesión del sujeto o en su control?

Lo anterior, si bien no permite demostrar de forma expresa que los bienes sin justificar del investigado se originan en un acto ilícito, si permiten demostrar de manera indiciaria que se está dando un delito de lavado de dinero.

Continuando con el ejemplo, el método de investigación financiera permite demostrar que el salario de funcionario público del investigado no le permite tener el estilo de vida de alto nivel que según sus gastos y sus bienes disfruta, de tal manera, que aún cuando no se pueda probar de forma directa el pago de un soborno por beneficios dado en virtud de su cargo público, si se demuestra que los bienes adquiridos y el estilo de vida que lleva no corresponden a sus ingresos lícitos, lo cual unido a otros elementos hacen presumir que tales recursos provienen de actividades ilícitas.

\section{La prueba en el método de análisis financiero}

La prueba utilizada en este tipo de investigación se refiere a todo documento que demuestre una disposición de fondos del investigado.

La prueba se divide en dos tipos:

a) Prueba Directa: artículos específicos, tales como transacciones financieras específicas descubiertas sobre el uso de fondos ilegales y las partes involucradas.

b) Prueba Indirecta: la más utilizada, tales como depósitos bancarios, los gastos, el uso del efectivo, entre otros.

Estos elementos probatorios permiten hacer el análisis de nivel de ingresos que debiera tener el investigado para llevar esa calidad de vida y determinar el saldo al descubierto que queda pendiente por cubrir según los ingresos declarados por él, los cuales se presumen posee un origen ilícito.

\section{Tipos de métodos de análisis financiero}

Existen diferentes métodos de análisis financiero, que de manera indirecta pretenden determinar si el investigado está cometiendo un delito de lavado de dinero con fondos provenientes de una actividad ilícita, que son:

\section{Método del efectivo}

El método del efectivo pretende seguirle el rastro al efectivo que maneja el investigado, por ser este el activo que más propensión de utilizarlo en este tipo de delito.

Este método se base en el principio de que el dinero se demuestra directamente o indirectamente en las cuentas bancarias, los bienes y los gastos del beneficiario, todo en última instancia se convierte en efectivo y se utiliza como efectivo.

En el método del efectivo se busca determinar si los ingresos ordinarios del investigado son suficientes para cubrir los depósitos bancarios y las compras en efectivo que realiza (ver figura 2). 


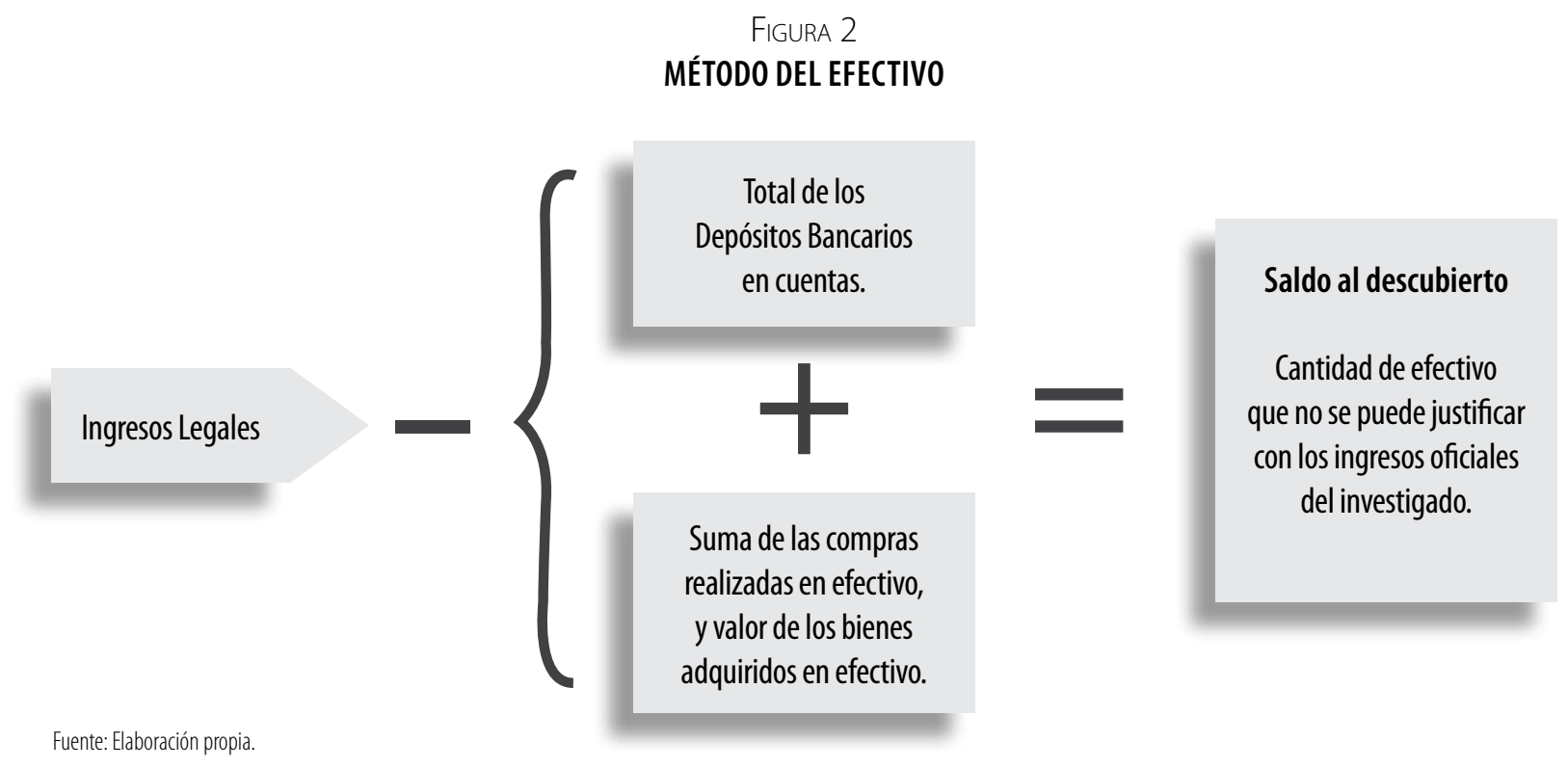

El saldo al descubierto demuestra que el investigado hace una disposición de efectivo mayor a la que sus ingresos le permiten, de tal manera que necesariamente debe existir otra fuente de ingresos que no está legalmente reportada.

Los activos más comunes que el investigador debe buscar se muestran en la Tabla 1.

TABLA 1

\section{ACTIVOS QUE EL INVESTIGADOR DEBE REVISAR}

\begin{tabular}{|l|l|}
\hline \multicolumn{1}{|c|}{ Activos circulantes } & \multicolumn{1}{|c|}{ Otros activos } \\
\hline Efectivo & Vehículos y demás bienes muebles \\
\hline Saldos en las cuentas bancarias & $\begin{array}{l}\text { Embarcaciones, aviones, y demás } \\
\text { de este tipo. }\end{array}$ \\
\hline Cuentas por cobrar & Bienes raíces, propiedades \\
\hline Inversiones Empresariales & $\begin{array}{l}\text { Participación en personas jurídicas, } \\
\text { sociedades mercantiles, asociacio- } \\
\text { nes, y demás figuras colectivas. }\end{array}$ \\
\hline Ingresos extraordinarios & Joyería \\
\hline & Ropa y otros bienes personales \\
\hline & Propiedad planta y equipo \\
\hline
\end{tabular}

Fuente: elaboración propia.
Dentro de las fuentes a las cuales se debe recurrir para obtener esta información, están:

- Movimientos bancarios, cantidad de cuentas que posee a su nombre, o bien aquellas que no estando a su nombre participa como autorizado para hacer disposición de fondos.

- Estudio de bienes muebles e inmuebles, así como cualquier otro inscribible en el Registro Público de la propiedad.

- Bases de datos de organismos públicos

- Bases de datos comerciales

- Vigilancia del investigado para identificar su rutina, costumbres, lugares que frecuenta y otros.

- Informantes

- Entrevistas

- Órdenes de cateo

- Monitoreo electrónico

- Operaciones encubiertas 
- Revisión de la basura en busca de recibos y comprobantes de pago de servicios o pago de bienes.

- Tarifas telefónicas de llamadas de larga distancia

- Pago de servicios de envíos de dinero al exterior, o bien, captación de remesas del exterior.

El método del efectivo analiza la manera en que el investigado utiliza el efectivo con el fin de identificar si este sobrepasa las fuentes de ingresos conocidas, y por ende, provienen de fuentes ilícitas y constituyen una manera de lavar activos.

\section{Método de rastreo de un depósito específico}

El método de rastreo de un depósito específico pretende seguir el uso que se le ha dado a un dinero que se presume proviene de una actividad ilícita, generalmente por un medio de pago.

En ese caso cuando las autoridades conocen de un pago que presuntamente proviene de una actividad ilícita buscan darle seguimiento, y verificar si el mismo se incluye dentro de los ingresos y gastos ordinarios del investigado.

Por ejemplo, se presume que una compañía A ha recibido un depósito por la suma de $\$ 15.000$ proveniente de un acto ilícito, por lo tanto se decide seguirle el rastro a dicho dinero.

De la revisión de los movimientos bancarios de la empresa se encuentra un depósito de dinero en efectivo sin detalle por $\$ 15.000$ pero de la revisión de los libros contables de la empresa A se denota que ésta nunca registró dicho ingreso, dejando ese saldo al descubierto y sin justificación o respaldos que se refieran a dicho depósito.
TABLA 2

\section{EJEMPLO DE COMPAÑÍA FICTICIA CON MÉTODO DE RASTREO DE DEPÓSITO ESPECÍFICO}

Compañía A

\section{Depósitos del 1 al 30 de octubre del 201X}

Ingresos según libros

\begin{tabular}{lrr} 
Corporación bananera & $\$$ & 1200,00 \\
Servituc & $\$$ & 1000,00 \\
HGT & $\$$ & 1750,00 \\
Oficentro & $\$$ & 650,00 \\
\hline Total ingresos libros & $\$$ & 4600,00
\end{tabular}

\section{Ingresos según bancos}

Depósito \# 123 Corp. Bananera \$ $\$ 1200,00$

Depósito \# 124 Servituc \$ 1000,00

Depósito \# 125 Sin detalle \$ $\$ 15000,00$

Depósito \# 126 HGT \$ 1750,00

Depósito \# 127 Oficentro \$ 650,00

Total ingresos según bancos $\$ 19600,00$

Monto no registrado en libros $\quad \$(15000,00)$

Fuente: Elaboración propia

Con este método se pretende rastrear un pago específico que se presume proviene de una actividad ilícita y que ha sido usado como una manera para el lavado, ya que efectivamente ingresa a la cuentas de una empresa pero al carecer de justificaciones ésta omite incluirlo dentro de sus registros contables.

\section{Método de depósito bancario}

Este método es uno de los más sencillos de utilizar y sin embargo, es de gran utilidad para probar de manera indirecta el enriquecimiento por la comisión de un delito, que puede ser lavado de dinero, corrupción o similares. En este método se buscan depósitos regulares de cantidades de dinero pequeñas pero que al sumar el total 
de depósitos durante un periodo de tiempo éste alcanza una suma importante de dinero que no puede ser justificada con los ingresos ordinarios.

Generalmente, se realizan depósitos pequeños para no despertar sospechas pero al contrarrestar la cantidad de depósitos con las fuentes conocidas de ingresos del investigado se genera un "monto al descubierto" que no puede ser justificado con los ingresos legales del investigado.

En este tipo de investigación se revisan los movimientos bancarios y compras en efectivo del investigado y se le aplica la siguiente fórmula que se presenta en la Tabla 3.

TABLA 3

FÓRMULA DE DEPÓSITOS BANCARIOS

Total de Depósitos Bancarios

(-) Transferencias y Re-Depósitos

(+) Total de compras en efectivo

(=) Depósitos y gastos en efectivo

(-) Fuentes conocidas de fondos

$(=) \quad$ Fondos de fuentes no identificadas

Fuente: Elaboración propia.

Pongamos por ejemplo, un empleado de un banco público que está utilizando su cargo para el lavado de dinero a favor de una organización criminal a cambio de una dádiva por ello, con lo cual se configuran dos delitos, el de lavado de dinero y el delito de corrupción, y que el presente método sirve para probar de manera indiciaria ambos delitos.
TABLA 4

\section{APLICACIÓN FICTICIA DE LA FÓRMULA DE DEPÓSITO BANCARIO}

(-) Total de Depósitos Bancarios ～～～2500000,00

(+) Transferencias y Re-Depósitos ～～ 2000000,00

(=) Total de compras en efectivo C 3000000,00

(-) Depósitos y gastos en efectivo — C 7500000,00

(=) Fuentes conocidas de fondos $\quad$ C 2000000,00

Depósitos de fuentes C 5500000,00
no identificadas

Fuente: Elaboración propia.

De la aplicación de este método se denota que el investigado ha realizado depósitos por \$5 500 000,00 sin que existan ingresos conocidos que lo respalden con lo cual se genera prueba indiciaria que junto con la demás prueba obtenida durante la investigación pueden probar la comisión del delito de lavado toda vez que se pretende pasar como lícitos recursos económicos y bienes de origen ilícito.

\section{Método del ingreso-gasto}

El método del gasto se enfoca en analizar los gastos en los que incurre el investigado y su comparación con los ingresos legítimos o declarados que posee el investigado.

En otras palabras, verificar si los ingresos conocidos del investigado son suficientes para cubrir sus gastos. 
FIGURA 3

\section{DIFERENCIA ENTRE GASTOS INCURRIDOS \\ E INGRESOS LEGALMENTE DECLARADOS}

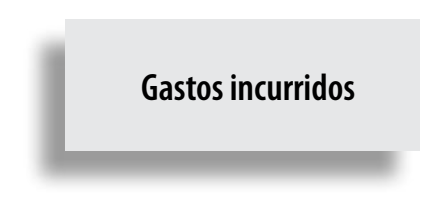

Fuente: Elaboración propia.

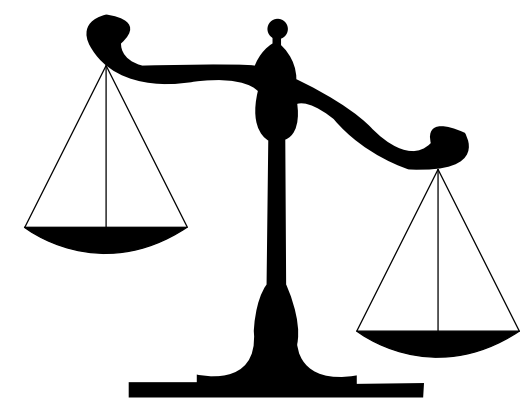

\section{Gastos legalmente} declarados
El desbalance en dicho equilibrio permite determinar si el investigado posee un saldo al descubierto, de gastos que no se pueden justificar con los ingresos ordinarios.

Se deben investigar las distintas fuentes de ingresos legalmente conocidas tales como:

- Salarios y sueldos

- Ingresos por rentas

- Intereses

- Dividendos

- Ganancias empresariales

- Pensión/pensiones vitalicias

- Fondos de otras fuentes conocidas

Otras fuentes de ingresos son:

- Disminución de saldos bancarios

- Venta de un activo

- Préstamos, regalos y herencias, premios

- Ganancias de juego (apuestas, entre otros)
Igualmente, el investigador debe determinar los gastos del investigado, tales como:

- Compra de activos

- Gastos personales (renta, servicios, hipoteca, ropa)

- Gastos por estilo de vida (viajes, vacaciones, hoteles, clubes, lujos)

- Seguros

- Tarjeta de Crédito

- Inversiones

- Incremento en las cuentas bancarias

- Disminución de los préstamos pendientes

- Otros

Una vez recopilada dicha prueba se procede a confrontar los gastos del investigado versus los ingresos legalmente conocidos, de la siguiente manera: 
TABLA 5

\section{MÉTODO INGRESO- GASTO}

Compras de Activos (bienes raíces, autos, embarcaciones, departamentos, sociedades)

(+) Reducción de deuda (préstamo u otros pasivos)

(+) Otros gastos (renta, viajes, teléfono, vacaciones)

(=) Gastos totales

Ingresos de fuentes legalmente conocidas (salario, préstamos,

(-) venta de activos, efectivo al inicio del periodo, saldo de cuentas bancarias)

(=) Fondos de fuentes no identificadas

Fuente: Elaboración propia.

En este método los abonos que el investigado realiza a sus deudas, tales como préstamos, hipotecas, tarjetas de crédito y demás se toman en cuenta dentro de los gastos incurridos, pues se requieren fondos para poder disminuir las deudas.

Igualmente, los gastos en que incurra en reparación y mantenimiento de los activos, como vehículos y reparaciones a la casa, así como, la adquisición de activos nuevos, y demás gastos importantes.

Una vez que se tienen todos estos gastos se hace una simple confrontación:

\section{Total gastos}

\section{(-) Ingresos legalmente declarados}

(=) Fondos de fuentes desconocidas

Por ejemplo un empleado bancario a quién la investigación reveló los datos presentados en la Tabla 6.

TABLA 6

\section{EJEMPLO FICTICIO DE EMPLEADO BANCARIO ANALIZADO CON EL MÉTODO INGRESO-GASTO}

Del 1 de enero al 30 de octubre

\section{Ingresos legalmente conocidos}

Salario $\zeta 8000000,00$

$\zeta 8000000,00$

\section{Gastos}

\begin{tabular}{ll} 
Abono a deudas & $\zeta 1000000,00$ \\
Abono a hipotecas & $\zeta 2000000,00$ \\
Remodelación de la vivienda & $\zeta 2500000,00$ \\
Pagos a la tarjeta de crédito & $\zeta 3000000,00$ \\
Pagos a la universidad & $\zeta 3000000,00$ \\
Pago de prenda & $\zeta 2000000,00$ \\
Cuentas de teléfono & $\zeta 300000,00$ \\
Vacaciones en Miami & $\zeta 12000000,00$ \\
\hline Total gastos & $\zeta 150000000,00$ \\
Fondos de fuentes desconocidas & $\zeta(70000000,00)$
\end{tabular}

Fuente: Elaboración propia. 
Como puede verse en la Tabla 6 del periodo de tiempo investigado se denota que el sospechoso ha incurrido en gastos que superan sus ingresos legalmente declarados en colones (7 000000,00$)$.

\section{Método del valor neto}

El método del valor neto es uno de los más completos y que requieren un análisis más profundo, pero que a su vez resulta muy convincente para probar la participación del investigado en delitos de lavado de dinero y corrupción.

Este método realiza un análisis comparativo de la condición económica del investigado antes de que se sospecha iniciara su participación en el acto delictivo, con la situación económica que posee a la fecha de investigación.

En otras palabras, se pretende demostrar una "mejoría" de la condición económica del investigado pese a que ha mantenido las mismas fuentes de ingresos y que no existen actividades que permitan justificar dicha mejoría.

El método del valor neto, se muestra en la Tabla 7

\section{TABLA 7 \\ MÉTODO DE VALOR NETO}

Activos

(-) Pasivos

(=) Valor neto

(-) Valor neto del año pasado

(=) Incremento del valor neto

(+) Gastos del estilo de vida actual

(=) Total de fondos e incremento del valor neto

(-) Fondos de fuentes conocidas

(=) Fondos de fuentes no conocidas

Fuente: Elaboración propia.
Para poder realizar este análisis se debe estudiar detalladamente cada una de las partidas que intervienen, tales como los activos del investigado antes de que presuntamente iniciara la actividad delictiva y después de ello, los pasivos que poseía y los que posee actualmente, los gastos ordinarios y el estilo de vida que llevaba antes de la presunta actividad delictiva y el que posee actualmente, y finalmente, determinar si existen modificaciones en los ingresos que justifiquen dichos cambios.

El análisis comparativo en que se basa este método se puede ver en la Figura 4.

Para estudiar cada una de estas partidas hay que tomar en cuenta diferentes aspectos, tales como:

\section{a) Análisis de los activos}

Se debe elaborar una lista detallada de los activos del investigado, lo más completa posible y para cada uno determinar lo siguiente:

- ¿ ¿Cuándo se adquirió el activo?

- ¿A quién se le adquirió?

- ¿Cuánto costó? -no interesa el valor de mercado, o el valor común, sino la cantidad exacta de lo que costo dicho activo-.

- ¿Cómo fue cancelado -efectivo, préstamo, tarjeta de crédito, entre otros-?

- ¿ ¿Cuál fue la fuente de fondos que se utilizó para su adquisición?

- ¿Qué documentación existe de la compra y donde se localiza?

El análisis de los activos permite determinar si durante el transcurso de tiempo durante el cual se sospecha ha acontecido el delito de lavado el 


\section{COMPARACIÓN DE CONDICIÓN ECONÓMICA ANTES VS DESPUÉS DE LA FECHA EN QUE PRESUNTAMENTE SE INICIÓ LA ACTIVIDAD DELICTIVA}

\begin{tabular}{|c|c|c|c|}
\hline $\begin{array}{l}\text { Condición } \\
\text { económica } \\
\text { del sospecho } \\
\text { ANTES } \\
\text { de la fecha en que } \\
\text { presuntamente } \\
\text { se inició la } \\
\text { actividad delictiva }\end{array}$ & $\begin{array}{l}\text { Ingresos } \\
\text { Únicamente su } \\
\text { salario (c } 800000) \\
\text { Estilo de vida } \\
\text { Normal acorde con una } \\
\text { familia de clase media, } \\
\text { vacaciones donde los } \\
\text { familiares, servicios } \\
\text { básicos, comunes. }\end{array}$ & $\begin{array}{l}\text { Deudas } \\
\text { Alto nivel de } \\
\text { deudas, hipoteca, } \\
\text { tarjeta de crédito, } \\
\text { prenda sobre el } \\
\text { carro, muchos } \\
\text { prestamos en } \\
\text { bancos y asociaciones } \\
\text { laborales. }\end{array}$ & $\begin{array}{l}\text { Gastos } \\
\text { Alto nivel de gastos, } \\
\text { esposa e hijos, natación } \\
\text { y otros deportes para sus } \\
\text { hijos, educación de sus } \\
\text { hijos, atraso en el pago } \\
\text { de servicios públicos e } \\
\text { impuestos municipales, } \\
\text { en síntesis, sus ingresos } \\
\text { no le son suficientes o } \\
\text { apenas dan para el gasto. }\end{array}$ \\
\hline $\begin{array}{l}\text { Condición } \\
\text { económica del } \\
\text { sospecho DESPUES } \\
\text { de la fecha en que } \\
\text { presuntamente } \\
\text { se inició la } \\
\text { actividad delictiva }\end{array}$ & $\begin{array}{l}\text { Estilo de vida } \\
\text { Alto nivel de vida, } \\
\text { vacaciones en el } \\
\text { extranjero o en hoteles } \\
\text { de lujo, asistencia de } \\
\text { clubes exclusivos para } \\
\text { la clase alta, lujos, y } \\
\text { gastos superfluos, } \\
\text { entre otros }\end{array}$ & $\begin{array}{l}\text { Deudas } \\
\text { Disminución } \\
\text { significativa de } \\
\text { las deudas, pago } \\
\text { de tarjeta, pago de } \\
\text { hipoteca, compra de } \\
\text { un nuevo vehículo y } \\
\text { demás similares. }\end{array}$ & $\begin{array}{l}\text { Gastos } \\
\text { Se sale sin problemas } \\
\text { con los gastos, mejoras } \\
\text { en la educación de los } \\
\text { hijos, incluso pago de } \\
\text { escuelas y colegios } \\
\text { privados o cursos de } \\
\text { natación o futbol } \\
\text {-que antes no podía } \\
\text { costear-, saldos } \\
\text { positivos en las cuentas } \\
\text { bancarias, contratación } \\
\text { de otros servicios. }\end{array}$ \\
\hline
\end{tabular}


investigado ha incrementado significativamente sus bienes, para sí o para terceros, y la manera en que estos fueron cancelados, incrementando la sospecha en aquellas compras realizadas en efectivo o a través de intermediarios, sean personas físicas u organizaciones como sociedades o asociaciones no gubernamentales, entre otras.

b) Estudio de los pasivos

Los pasivos comprenden todas las obligaciones y deudas que posee el investigado, y sobre los cuales se debe determinar lo siguiente:

- ¿A cuánto ascendían las deudas del investigado antes de que presuntamente iniciara la comisión del delito?

- ¿A cuánto ascienden actualmente las deudas del investigado?

- ¿Cuándo se origina la deuda?

- ¿Posee el investigado deudas con tarjetas de créditos? ¿Por qué monto?

- ¿Cuál fue el propósito de la deuda?

- ¿Cómo fue utilizado el dinero de la deuda y donde fue depositado?

- ¿El investigado ha realizado pagos extraordinarios o importantes a sus deudas?

- ¿Qué garantía fue ofrecida para respaldar dicha deuda?

- ¿Qué documentación existe de la transacción y dónde se encuentra?

- ¿Quién fue el prestamista o acreedor?
El estudio de los pasivos resulta de vital importancia, pues de ellos se pueden obtener dos hallazgos relevantes para la investigación, pues por un lado permite encontrar un "motivo" para la comisión del delito de lavado, ya que si el investigado posee un alto nivel de endeudamiento muy superior a sus ingresos ordinarios, resulta altamente probable que la presión económica lo llevare a participar de esta actividad ilícita, con el fin de obtener ingresos extra que le permitan cubrir sus deudas.

A su vez, permite demostrar la comisión del delito de lavado cuando se puede constatar que las deudas del investigado se han reducido significativamente durante el tiempo en que se presume se ha cometido el delito, pese a que no se posee ingresos adicionales que justifiquen dicha mejoría en la capacidad de pago del investigado.

c) Análisis del gasto

En el caso de los gastos interesa determinar si durante el periodo de tiempo en que se presume se ha cometido el delito el investigado ha aumentado significativamente sus gastos, o bien, cuál es el propósito de dichos gastos.

Sobre los gastos se debe determinar lo siguiente:

- ¿Cuál fue el motivo del gasto?

- ¿Para qué se incurrió?

- ¿Quién fue la persona que lo hizo?

- ¿De dónde se obtuvieron los fondos para pagar el gasto?

- ¿Qué documentación, tales como recibos o facturas existen y donde se encuentran? 
- ¿Qué gastos están vinculados con su estilo de vida actual?

- ¿Qué gastos se incurren en bienes de "lujo"?

- ¿Qué nuevos gastos fijos posee el investigado?

- $\quad$ ¿Ha incurrido el investigado en gastos importantes durante el tiempo de la investigación?

El análisis de los gastos permite determinar si ha habido un cambio significativo del estilo de vida que llevaba el investigado desde la fecha en que presuntamente se ha iniciado la comisión del delito de lavado de dinero, pese a que sus ingresos se han mantenido relativamente estables.

En este análisis se debe prestar especial atención a los gastos superfluos o bienes de lujo que el investigado antes no poseía y ahora sí, y aún más, si antes del periodo de investigación el investigado poseía recursos limitados que hacían suponer que sus ingresos no le alcanzaban y de un tiempo en adelante, su situación simplemente mejoró y paso de tener ingresos ajustados a permitirse bienes y servicios considerados de lujo.

Igualmente, a gastos importantes en que hay a incurrido durante el tiempo en que se presume se ha cometido el delito, y aquellos que paga en efectivo ya sea que los utilice directamente o estén para provecho de terceras personas como familiares, amigos y demás.

d) Investigación de los ingresos

Finalmente, se debe revisar los ingresos del investigado a fin de determinar lo siguiente:

- ¿ ¿Cuáles son las fuentes declaradas de ingresos del investigado?
- ¿Existen otras fuentes extraordinarias de ingresos?

- ¿Se ha dado una mejoría importante en los ingresos del investigado durante el tiempo investigado?

- ¿Existen fuentes de ingresos lícitas que pudieren justificar el incremento en los activos y gastos y la disminución de las deudas del investigado?

La investigación de los ingresos permite descartar que existan fuentes lícitas que justifiquen la mejoría significativa en la calidad de vida del investigado y que por lo tanto, no se encuentre frente a la comisión de un delito, pues dichos gastos y pagos poseen una razón justificada para darse, ya sea por un incremento en los ingresos, la obtención de una herencia, el ganar un premio económico y demás.

Una vez que se ha descartado que estos hechos legales hayan acontecido, resulta posible cuestionar la mejoría en la calidad de vida del encausado, pues no existen ingresos declarados que justifiquen dicha situación.

Finalmente, en el método del valor neto se procede a realizar el análisis comparativo de la situación económica del investigado antes de iniciar la presunta actividad delictiva contra la situación económica que posee actualmente.

e) Ejemplo práctico de este método

Continuemos con el ejemplo del empleado de un banco público que de la aplicación de este análisis se pudo determinar los siguientes datos: 
TABLA 8

\section{EJEMPLO FICTICIO DE LA SITUACIÓN ECONÓMICA DEL INVESTIGADO ANTES DE LA FECHA EN QUE PRESUNTAMENTE INICIÓ LA ACTIVIDAD DELICTIVA}

Método del valor neto

Del enero a diciembre del año A

Activos

Pasivos

\begin{tabular}{|c|c|c|c|}
\hline Saldos en las cuentas bancarias & \& 250000,00 & Tarjetas de crédito & \& 2000000,00 \\
\hline Vivienda & \& 35000000,00 & Reconversión de deuda con tarjeta & \& 1200000,00 \\
\hline Vehículo & \& 1000000,00 & Deudas en bancos & \& 5000000,00 \\
\hline \multirow[t]{7}{*}{ Total activos } & \& 36250000,00 & Deudas en organizaciones laborales & \& 2000000,00 \\
\hline & & Hipoteca & \& 30000000,00 \\
\hline & & Prenda del carro & द 800000,00 \\
\hline & & Total pasivos & ¿ 41000000,00 \\
\hline & Total activos & 36250000,00 & \\
\hline & Total pasivos & 41000000,00 & \\
\hline & Valor Neto año A & $(4750000,00)$ & \\
\hline
\end{tabular}

Fuente: Elaboración propia.

TABLA 9

EJEMPLO FICTICIO DE LA SITUACIÓN ECONÓMICA DEL INVESTIGADO DESPUÉS

DE LA FECHA EN QUE PRESUNTAMENTE INICIÓ LA ACTIVIDAD DELICTIVA

\begin{tabular}{|c|c|c|c|c|}
\hline \multicolumn{5}{|c|}{ Método del valor neto } \\
\hline Activos & \multicolumn{4}{|c|}{ Pasivos } \\
\hline Saldos en las cuentas bancarias & $\zeta 8000000,00$ & Tarjetas de crédito & $\zeta$ & 0 \\
\hline Vivienda & $\zeta 35000000,00$ & Reconversión de deuda con tarjeta & $\zeta$ & 0 \\
\hline Vehículo & $\zeta 2000000,00$ & Deudas en bancos & $\zeta$ & 0 \\
\hline \multirow[t]{7}{*}{ Total activos } & ל 45000000,00 & Deudas en organizaciones laborales & $\zeta$ & 0 \\
\hline & & Hipoteca & \multicolumn{2}{|c|}{ \& 30000000,00} \\
\hline & & Prenda del carro & $\zeta$ & 0 \\
\hline & & Total pasivos & $\xi 3$ & \\
\hline & Total activos & 45000000,00 & & \\
\hline & Total pasivos & $\zeta \quad(30000000,00)$ & & \\
\hline & Valor Neto año B & 15000000,00 & & \\
\hline
\end{tabular}

Fuente: Elaboración propia. 


\section{TABLA 10 \\ COMPARACIÓN PARA DETERMINAR VARIACIÓN EN EL VALOR NETO DE LA SITUACIÓN FINANCIERA DEL INVESTIGADO}

\begin{tabular}{|c|c|c|}
\hline \multicolumn{3}{|c|}{ Método del valor neto } \\
\hline & Valor neto año A & ${ }^{*} \zeta 4750000,00$ \\
\hline$(+)$ & Valor neto año B & $\zeta 15000000,00$ \\
\hline$(=)$ & Incremento en el patrimonio & $\zeta 19750000,00$ \\
\hline$(+)$ & Gastos fijos del investigado año B & $\zeta 15000000,00$ \\
\hline$(=)$ & $\begin{array}{l}\text { Total incremento patrimonio } \\
\text { y gastos fijos }\end{array}$ & $\measuredangle 34750000,00$ \\
\hline
\end{tabular}

*El saldo negativo que poseía en el año A se suma, pues implica que el investigado utilizó recursos para "cubrir el faltante"y por lo tanto debe considerarse como suma, pues forma parte del incremento en los ingresos utilizados para cancelar dicha deuda.

Fuente: Elaboración propia.

Total incremento patrimonio y gastos fijos $\quad \$ 34750000,00$

(-) Fuentes conocidas de ingresos

(Salario de $800000 \times 12$ meses)

$\zeta 9600000,00$

(=) Fondos de fuentes desconocidas de ingresos $\$ 25150000,00$

Fuente: Elaboración propia.

En este caso, el investigado posee $\$ 25150000,00$ en activos y gastos que no puede justificar con sus ingresos ordinarios, lo que demuestra que existe otra fuente de ingresos que no ha sido legalmente declarada, que le permite cancelar las deudas que poseía anteriormente e incluso incrementar sus gastos y nivel de vida.

Como puede verse este método permite demostrar de manera muy completa, pues incluye activos, pasivos y gastos que el investigado ha percibido una mejora en sus condiciones de vida que no se explican con sus ingresos legítimos.
De tal manera, que si bien este sólo hecho no demuestra que la comisión de un delito si constituye prueba indiciaria de que los mismos provienen de una actividad delictiva, como podría ser el lavado de dinero, y que unido a otras indagaciones puede contribuir a que se condene a una persona investigada por esta actividad ilícita.

\section{Importancia de los métodos de investigación financiera}

Los métodos de investigación financiera permiten crear prueba indiciaria para demostrar que el investigado está percibiendo un enriquecimiento que no encuentra justificación en sus ingresos legalmente declarados, y que por lo tanto, puede presumirse que los mismos provienen de un acto ilícito.

Igualmente, puede demostrar el motivo que origino que el investigado incurriera en este tipo de actividades, tales como un fuerte endeudamiento previo, un salario insuficiente para cubrir los gastos y gustos del investigado, y demás, elementos que pudieren demostrar que ante la situación económica el investigado pudo recurrir a participar en este tipo de actividades delictivas para percibir los ingresos faltantes.

Para las investigaciones por delitos de lavado de dinero, estos métodos permiten complementar otras pruebas que pueden vincular la clara "mejoría" de la calidad de vida del investigado con la comisión de este delito.

Si bien, no estamos ante una prueba directa en donde conste el pago, lo cual resulta muy difícil pues por lo general se realiza de forma tal que no quede evidencia, si permite demostrar que existen hechos cuestionables suficientes que se razonablemente se puede cree que son beneficios por participar en una actividad ilícita, como lo sería el delito de lavado de dinero. 
Esta prueba resulta muy clara, y raras veces refutable, pues por lo general el acusado no posee medios para demostrar el origen lícito de los ingresos que le han permitido llevar un nivel de vida que por lo general no es acorde con el que le permitirían sus ingresos.
Estos métodos se enfocan en distintas áreas de estudio, y se pueden explicar para comprender mejor su función en la Tabla 12:

\section{RESUMEN DE MÉTODOS DE INVESTIGACIÓN FINANCIERA}

\begin{tabular}{|c|c|}
\hline Método de investigación & Explicación \\
\hline a. Método del efectivo & $\begin{array}{l}\text { Este método se enfoca en el uso del efectivo que hace el investigado, en delitos como el narcotráfico, por ejemplo, la fuente } \\
\text { primaria de ingresos es el efectivo, (no se compra droga con tarjeta de crédito o con bienes), por lo que el uso excesivo } \\
\text { de efectivo para adquirir bienes y servicios puede tomarse como un indicio de la comisión del delito de lavado de dinero } \\
\text { proveniente del narcotráfico. } \\
\text { De tal manera, que rastreando el uso del efectivo que hace el investigado se puede demostrar que la cantidad que utiliza es } \\
\text { mayor a la que posee por sus fuentes de ingresos legales. }\end{array}$ \\
\hline $\begin{array}{l}\text { b. Método de rastreo } \\
\text { de un depósito específico }\end{array}$ & $\begin{array}{l}\text { Este método se utiliza cuando ya se está realizando una investigación y se detecta un depósito que proviene de actividades } \\
\text { ilícita, y se pretende "lavar", por lo que se le da un seguimiento especial en las cuentas del investigado, y se logra determinar } \\
\text { que dicho depósito no se origina en las fuentes de ingresos legalmente declaradas por el investigado. } \\
\text { Se pretende "rastrear" dicho depósito desde el momento en que ingresa a las cuentas del investigado con el fin de identificar } \\
\text { el uso que se hace de él. }\end{array}$ \\
\hline $\begin{array}{l}\text { c. Método de Depósito } \\
\text { bancario }\end{array}$ & $\begin{array}{l}\text { En este método se estudian todos los depósitos, transferencias, re-depósitos, y demás similares que realiza el investigado } \\
\text { en sus cuentas bancarias, con el fin de determinar que se realizado una cantidad excesiva de estos movimientos que no se } \\
\text { pueden justificar a través de los ingresos ordinarios del investigado y que presumen una estrategia para "lavar" dichos dineros } \\
\text { e ingresarlos a la economía formal. }\end{array}$ \\
\hline d. Método del Ingreso-Gasto & $\begin{array}{l}\text { En este método se realiza un análisis comparativo entre los ingresos y gastos del investigado, tomando como gasto el pago } \\
\text { de deudas, adquisición de activos, gastos superfluos, contratación de servicios de lujo, y demás que impliquen una "mejoría" } \\
\text { o incremento en el nivel de vida del investigado, con el fin de determinar que éste es superior al que posee una persona con } \\
\text { sus mismos ingresos, y que no encuentra explicación en los ingresos ordinarios del encausado. }\end{array}$ \\
\hline e. Método del Valor Neto & $\begin{array}{l}\text { El método del valor neto realiza un análisis comparativo entre las condiciones financieras del investigado antes de la fecha } \\
\text { en que presuntamente inició la actividad delictiva, y las condiciones de vida que posee después de la fecha en que se inició } \\
\text { la comisión de dicho delito. } \\
\text { Con este método se pretende demostrar que el investigado, pese a que ha poseído los mismos ingresos, ha logrado una } \\
\text { "mejoría" inexplicable de su calidad de vida, ha disminuido sus deudas y aumentado sus gastos, sin que no haya una fuente } \\
\text { de recursos que lo respalden, por lo cual se puede presumir que este saldo al descubierto proviene de un delito de lavado } \\
\text { de dinero. } \\
\text { lgualmente, se puede demostrar el "motivo", pues una situación económica difícil, con un alto endeudamiento y un salario } \\
\text { que no alcanza para cubrir los gastos, constituyen una causa por la cual el investigado inició dicha actividad delictiva, con el } \\
\text { fin de obtener los recursos que le hacían falta para cubrir sus necesidades. }\end{array}$ \\
\hline
\end{tabular}

Fuente: Elaboración propia. 
En síntesis se puede decir que estos métodos son una excelente fuente de prueba indiciaria que unida a las demás pruebas permiten demostrar la comisión del delito de lavado de dinero, u otros similares.

\section{CONCLUSIONES}

De lo expuesto anteriormente podemos llegar a conclusiones como que el delito de lavado de dinero o blanqueamiento de capitales se configura cuando se pretenden ingresar al ciclo de la economía normal los ingresos que provienen de actividades ilícitas como fuentes de ingresos legales.

Los métodos de investigación financiera permiten detectar y probar a través de prueba indiciaria la comisión del delito de lavado de dinero por parte del investigado.

Estos métodos de investigación permiten demostrar que los activos, gastos y nivel de vida que posee el investigado no están acordes con sus ingresos legalmente declarados y por lo tanto, posee un saldo al descubierto que no se puede justificar con las fuentes de ingresos conocidas, por lo que presumiblemente provienen de una actividad ilícita, como lo sería el lavado de dinero.

Dentro de estos métodos se analizan los siguientes tipos: Método del efectivo, Método de rastreo de un depósito específico, Método de Depósito bancario, Método del Ingreso-Gasto y Método del Valor Neto.

El método de efectivo se enfoca en estudiar el uso del efectivo que realiza el investigado que generalmente es mayor al que posee a través de sus fuentes normales, el método de rastreo de un depósito específico pretende seguir la pista de un depósito especifico que se sospe- cha proviene de una actividad ilícita y que se quiere "lavar", el método de depósito bancario estudia todos los depósitos bancarios del investigado para demostrar un alto manejo de recursos superiores a sus ingresos ordinarios, el método del ingreso-gasto, compara los gastos en los que incurre el investigado con sus ingresos ordinarios, a fin de demostrar un nivel de gastos mayores a los que legalmente podría costear y finalmente, el método del valor neto, pretende hacer una comparación entre el nivel de vida que poseía el investigado antes de la fecha en que posiblemente inició la actividad lucrativa y el nivel de vida que posee después, con el fin de demostrar que ha existido una mejoría en su calidad de vida que no se justifica con sus ingresos declarados, los cuales generalmente se mantienen estables.

Los resultados de estos métodos no son prueba directa, no obstante, son una importante fuente de prueba indirecta, ya que difícilmente el investigado puede demostrar el origen lícito de dichos fondos, o justificar la "mejoría" en su nivel de vida.

De tal manera, que unidos a otra prueba, permiten detectar y probar la comisión del delito de lavado de dinero de parte del investigado.

\section{REFERENCIAS}

Asamblea Legislativa. (2001). Ley Nº 8204 denominada Reforma integral Ley sobre estupefacientes, sustancias psicotrópicas, drogas de uso no autorizado, actividades conexas, legitimación de capitales y financiamiento al terrorismo.

The Departament of the Treasury, Técnicas de Detección e Investigación de la Corrupción Pública. Seminario Impartido del 20 al 24 de junio del 2011, San José, Costa Rica. 
RNA Revista Nacional de Administración

Alonso, L. A. (2011). Marco Internacional Regulador de Prevención de Capitales y Financiación del Terrorismo. En F. Ceddet, Curso Superior de Prevención de Blanqueo de Capitales, 7 edición (págs. 2-74). Madrid: Fundación Ceddet.

Centro de Investigación Jurídica. (1998). El Delito de Legitimacion de Capitales. San José, Costa Rica: Universidad de Costa Rica.

Recibido: 26 de mayo de 2012

Aceptado: 22 de junio de 2012

1743 (2), Julio - Diciembre, 2012 